Article

\title{
Investigation of the Biocidal Performance of Multi-Functional Resin/Copper Nanocomposites with Superior Mechanical Response in SLA 3D Printing
}

\author{
Nectarios Vidakis ${ }^{1}$, Markos Petousis ${ }^{1, * \mathbb{D}}$, Emmanuel Velidakis ${ }^{1}$, Nikolaos Mountakis ${ }^{1}$, Dimitris Tsikritzis ${ }^{2} \mathbb{D}$, \\ Aikaterini Gkagkanatsiou ${ }^{1}$ and Sotiria Kanellopoulou ${ }^{1}$ \\ 1 Mechanical Engineering Department, Hellenic Mediterranean University, Estavromenos, \\ 71410 Heraklion, Greece; vidakis@hmu.gr (N.V.); m.velidakis@hmu.gr (E.V.); mh90@edu.hmu.gr (N.M.); \\ tm6759@edu.hmu.gr (A.G.); tm6751@edu.hmu.gr (S.K.) \\ 2 Department of Electrical \& Computer Engineering, Hellenic Mediterranean University, \\ 71410 Heraklion, Greece; dtsikritzis@hmu.gr \\ * Correspondence: markospetousis@hmu.gr; Tel.: +30-2810-37-9227
}

Citation: Vidakis, N.; Petousis, M.; Velidakis, E.; Mountakis, N.;

Tsikritzis, D.; Gkagkanatsiou, A.; Kanellopoulou, S. Investigation of the Biocidal Performance of Multi-Functional Resin/Copper Nanocomposites with Superior Mechanical Response in SLA 3D Printing. Biomimetics 2022, 7, 8 . https://doi.org/10.3390/ biomimetics7010008

Academic Editor: Jose Luis Chiara

Received: 12 December 2021

Accepted: 31 December 2021

Published: 2 January 2022

Publisher's Note: MDPI stays neutral with regard to jurisdictional claims in published maps and institutional affiliations.

Copyright: (C) 2022 by the authors. Licensee MDPI, Basel, Switzerland. This article is an open access article distributed under the terms and conditions of the Creative Commons Attribution (CC BY) license (https:// creativecommons.org/licenses/by/ $4.0 /)$.

\begin{abstract}
Metals, such as silver, gold, and copper are known for their biocidal properties, mimicking the host defense peptides (HDPs) of the immune system. Developing materials with such properties has great importance in medicine, especially when combined with 3D printing technology, which is an additional asset for various applications. In this work, copper nanoparticles were used as filler in stereolithography (SLA) ultraviolet (UV) cured commercial resin to induce such biocidal properties in the material. The nanocomposites developed featured enhanced mechanical responses when compared with the neat material. The prepared nanocomposites were employed to manufacture specimens with the SLA process, to be tested for their mechanical response according to international standards. The process followed was evaluated with Scanning Electron Microscopy (SEM), Atomic Force Microscopy (AFM), energy-dispersive X-ray spectroscopy (EDS), and thermogravimetric analysis (TGA). The antibacterial activity of the fabricated nanocomposites was evaluated using the agar-well diffusion method. Results showed enhanced mechanical performance of approximately $33.7 \%$ in the tensile tests for the nanocomposites filled with $1.0 \mathrm{wt} . \%$. ratios, when compared to the neat matrix material, while this loading showed sufficient antibacterial performance when compared to lower filler loadings, providing an added value for the fabrication of effective nanocomposites in medical applications with the SLA process.
\end{abstract}

Keywords: stereolithography (SLA); 3D printing; antibacterial; additive manufacturing (AM); copper $(\mathrm{Cu})$; resin; mechanical; nanocomposites

\section{Introduction}

Microbial contamination of air, water, and soil by a variety of microorganisms produces problems in both living and non-living things, as well as in public health and industry. Antibiotic resistance genes have thus become more frequent in a wide range of microorganisms, including people and animals [1]. The host defense peptide (HDP) has mechanisms to inhibit or kill bacteria, and their physicochemical characteristics are imitated by various materials, such as copper, silver, titanium, and zinc, which exhibit antibacterial efficacy [1,2]. Metal Nanoparticles (NPs) are the most promising in this field, having demonstrated considerable antibacterial characteristics and being more commonly used in industry [3]. Still, the mechanisms underlying metallic nanostructures' biocidal action are not fully understood [4].

The development of additive manufacturing (AM) has gained interest from both academic and industrial perspectives [5,6]. In the past decades, a wide range of AM techniques have been invented and commercialized, utilizing a variety of polymeric, composite, and 
metal materials [7-9]. Among the most known and those with enough impact in industrial applications technologies are Fused Filament Fabrication (FFF), stereolithography (SLA), and Selective Laser Sintering (SLS) [10-13]. All these technologies differ in their technical parameters and utilized materials; however, they all share the same operating principle of layer-by-layer manufacturing [14,15]. While FFF has gained the greatest market share and interest in composite material development, SLA is gaining continuous advancement $[16,17]$.

SLA 3D printing technology is an AM method that utilizes resins in liquid form, which are introduced into a tank with a transparent bottom [18-20]. The laser light is electronically driven through reflective mirrors to the bottom of the tank [21-23]. The laser spot follows a path specified by the software at each layer. This introduction of light enables the polymerization of the photosensitive resin, and the process is repeated to fabricate each layered component $[17,21,24,25]$. As a result of the SLA 3D printing method, the fabricated parts are solid, in contrast to the typically hollowed parts of other 3D printing methods [26-28]. The laser spot size enables the fabrication of micro-sized layers, usually ranging from 25 to $100 \mu \mathrm{m}$, resulting in the manufacturing of parts with smooth and consistent surface and structure [23]. Additionally, the specifications of the SLA 3D printing process enhance the capability of manufacturing complex geometry structures [12,29].

SLA, followed by AM techniques such as DLP and LCD are mostly utilized in medical, dental, and coherent implementations [21,22]. Prototyping applications of sectors, such as automotive and aerospace, also utilize SLA technology; however, in dental and medical utilization, components are additionally fully operational $[30,31]$. The recent pandemic has led to a wide range of problems in many economic sectors, including the sensitivity of the supply chain to such situations [26,32]. The worldwide 3D printing community has exhibited the forward momentum of AM by reducing the deficits, and in many cases, eliminating them [32,33]. Sufficient case studies have been presented regarding the manufacturing of face shields and respiratory components during this period [34,35], initiating a potential for further 3D printing implementations in the medical sector [11,36].

Medical, dental, and other similar applications require excellence in design, manufacturing, quality control, and the entire production process [37-39]. Most strict regulations worldwide are introduced for medical devices, and the materials used in such applications are evaluated in depth for their reliability, safety, and effectiveness [39]. The development of such composite materials to be introduced in SLA AM technology could enable the development of stiff reliable composites with advanced electrical conductivity properties [40-42], antibacterial performance [14,31,43], etc. In this way, the manufacturing capabilities would be greatly increased, while the manufacturing cost could be reduced with the introduction of AM technology.

Nanotechnology can introduce such specifications when used in composites fabrication [44]. Extensive research has been conducted on the introduction of nanoparticles in various forms, sizes, and combinations $[40,45,46]$. Nanocomposites have been widely introduced in FFF materials $[13,14,47,48]$, while the development of nanocomposites in SLA materials is still not widely investigated $[12,13,23]$. Copper $(\mathrm{Cu})$ is a metallic material that has been used in several applications over the years [49-51]. Its ductile behavior and antibacterial properties introduced a definite advantage for composites' development. Copper nanoparticles have been introduced in matrix materials for nanocomposites' fabrication, for catalysts due to large surface-to-volume ratio, antibacterial surfaces, and electrical applications [52]. Sufficient research has also been conducted on AM, mainly in materials for the FFF process [53-56].

This work is an attempt to develop materials suitable for SLA 3D printing, mimicking the properties of HDPs, to be used in engineering and medical applications. Copper's biocidal properties were used to accomplish this. A common ultraviolet (UV)-cured photosensitive SLA resin was used as a matrix material, and it was filled with copper $(\mathrm{Cu})$ nanoparticles at various loadings. Low filling ratios were selected for the study. The method used common laboratory equipment to investigate the potential of nanocomposites' 
fabrication. To the best of the authors' knowledge, no similar study has been presented in literature so far on the manufacturing of SLA nanocomposites with copper nanofillers for plausible implementation in medical applications. The antibacterial performance of all the nanocomposites developed was verified with the laboratory process followed in this work. Additionally, the nanocomposites developed exhibited enhanced mechanical performance when compared with the matrix material. Specimens were manufactured with the SLA process and assessed according to international standards. Their mechanical, thermal, and morphological properties were studied. Thus, the novelty of the work is related to the process followed, and the nanocomposites developed, with a common low-cost commercial UV resin for the SLA 3D printing process, which can be exploited in various demanding applications, requiring enhanced mechanical properties in combination with antibacterial performance. The results show the potential of the commercial SLA UV-cured resin $\mathrm{Cu}$ nanocomposites, as the mechanical performance was enhanced in all filler loadings studied.

\section{Materials and Methods}

Figure 1 summarizes the steps followed in this work for the preparation of the nanocomposites, the manufacturing of the specimens, and their characterization processing.

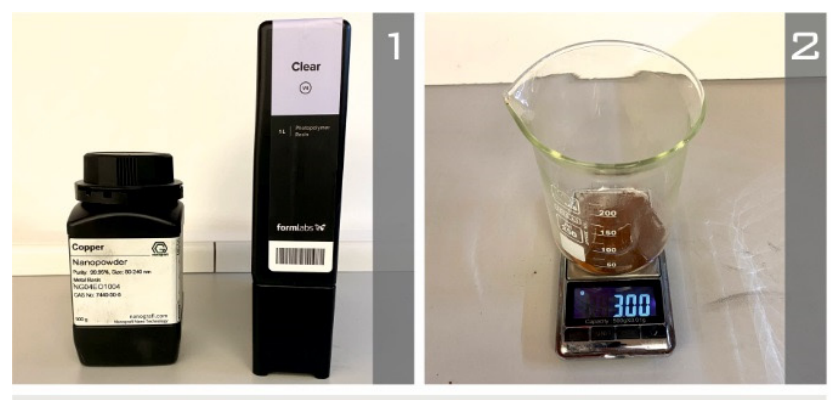

Preparation of the Nanocomposites' Components
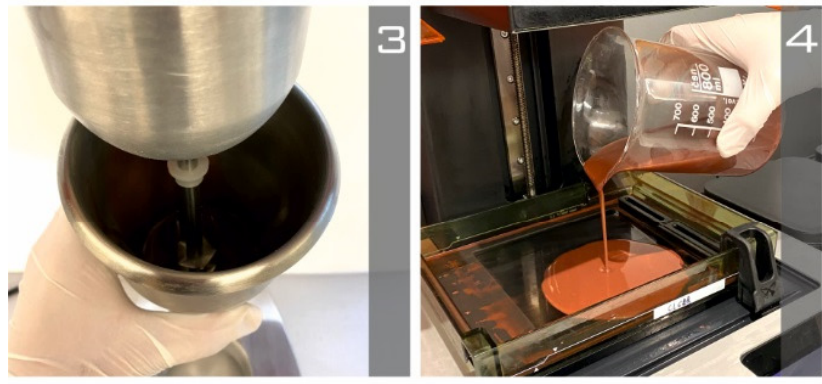

Shear Stress Stirring and SLA Printing
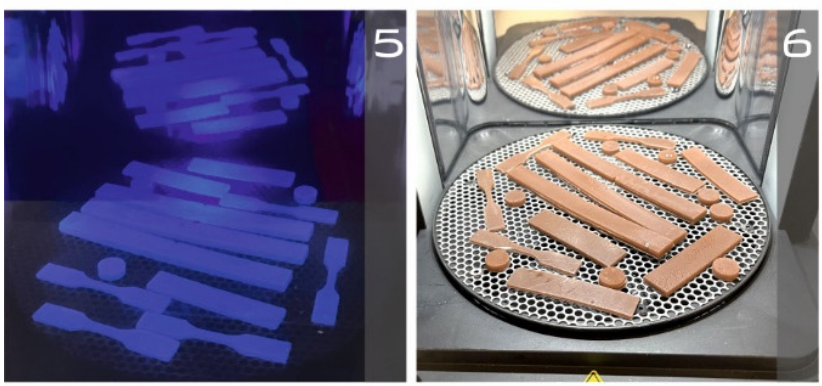

Specimen UV Healing and Inspection
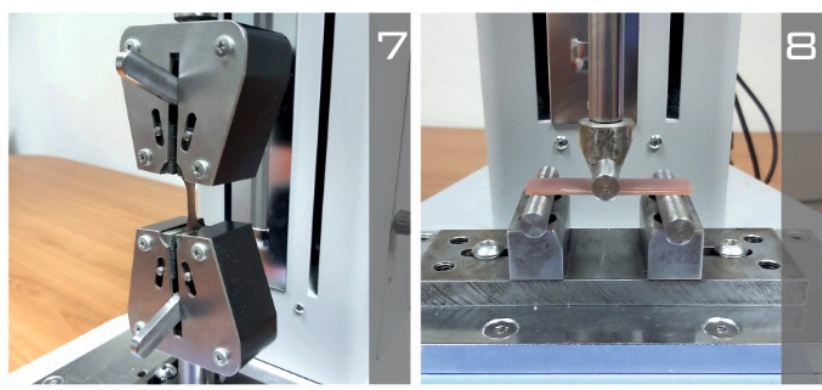

Mechanical Properties Testing and Evaluation
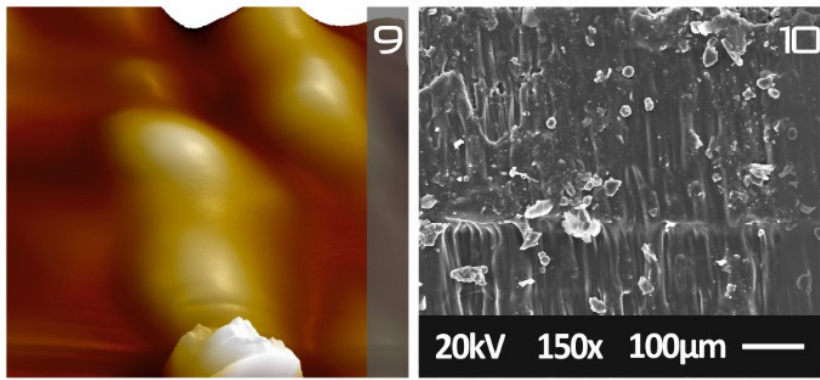

Morphological and Microfairule Characterisation
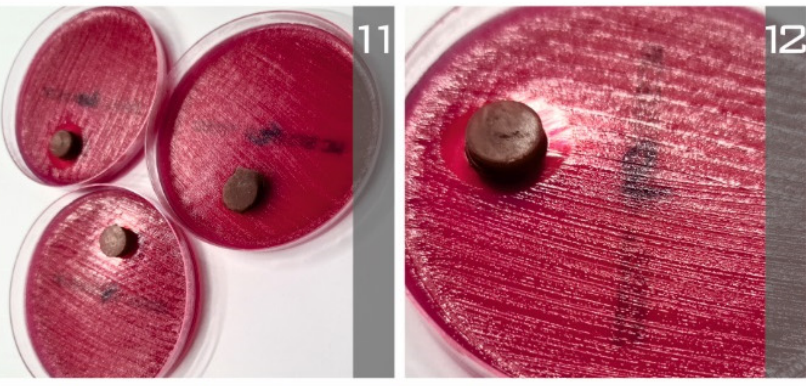

Evaluation of Antibacterial Performance

Figure 1. Workflow presentation of the followed processing using images captured during the study. 


\subsection{Materials}

The matrix material selected for the current study was Formlabs Standard Clear V4 (Formlabs Inc., Somerville, Massachusetts, United States) procured from a local supplier. Standard clear V4 resin (SC) is a commercially available product, and according to the safety data sheet consists of 55-75\% urethane di-methacrylate, 15-25\% methacrylate monomer(s), and less than $0.9 \%$ diphenyl (2,4,6-trimethybenzoyl) phosphine oxide. Copper nanoparticles $(\mathrm{Cu})$ were used as fillers for the nanocomposite fabrication. $\mathrm{Cu}$ nanopowder was procured from Nanografi (Nanografi Inc., Ankara, Turkey), and the size of the nanoparticles ranged from $80 \mathrm{~nm}$ to $240 \mathrm{~nm}$ with a purity of $99.95 \%$.

\subsection{Nanocomposites and Specimens Fabrication}

Nanocomposites were prepared using a high-rotational-speed laboratory mixer, which enabled high shear forces during the mixing procedure. $\mathrm{Cu}$ nanoparticles were weighed and introduced into the SC resin matrix material at filling ratios of $0.5 \mathrm{wt} . \%, 1.0 \mathrm{wt} . \%$ and $2.0 \mathrm{wt}$ \% respectively. The mixing process of each nanocomposite had a duration of $30 \mathrm{~min}$ to achieve the optimum dispersion of the nanoparticles in the nanocomposites. Before the uncured nanocomposites were poured into the 3D printer tank, they were degassed using a laboratory vacuum chamber. An SLA 3D printer was used for the specimens' fabrication. Formlabs Form 2 (Formlabs Inc., Somerville, Massachusetts, United States), equipped with a resin tank of Formlabs Tank LT, was employed, which is a 3D printer equipped with a laser light source with a wavelength of $450 \mathrm{~nm}$ and a laser spot of $150 \mu \mathrm{m}$. In Preform software version 3.16 (Formlabs Inc., Somerville, Massachusetts, United States), the necessary G-code file and layer height setup were set at $100 \mu \mathrm{m}$. All specimens were placed and oriented so that the widest side had a direct touch on the build platform, while for the light source setting, the default setting for the matrix material was used for all studied nanocomposites. The 3D printing process was followed by thorough washing of the specimens in an isopropyl alcohol (IPA) bath with $90 \%$ purity, in a Formlabs Form Wash machine for $10 \mathrm{~min}$. The specimens were washed and thoroughly dried in room conditions $\left(22^{\circ} \mathrm{C}, 50 \% \mathrm{RH}\right)$. Then they were placed in a UV curing chamber, i.e., a Formlabs Form Cure (Formlabs Inc., Somerville, Massachusetts, United States) machine. Surface curing of the specimens was conducted for $30 \mathrm{~min}$ at $60^{\circ} \mathrm{C}$, according to the manufacturer's specifications for the matrix material. Figure 2 shows the fundamental 3D printing settings used in this work.

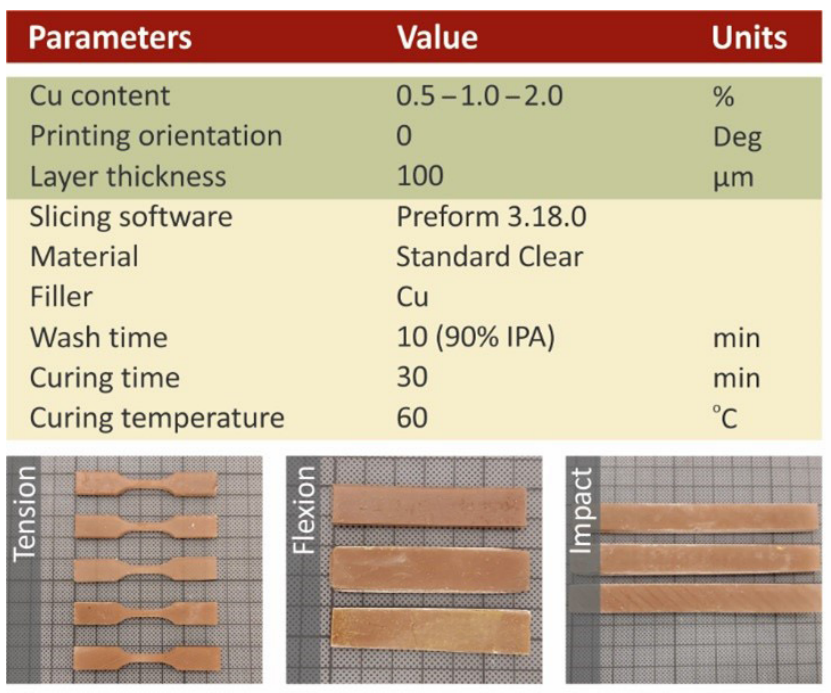

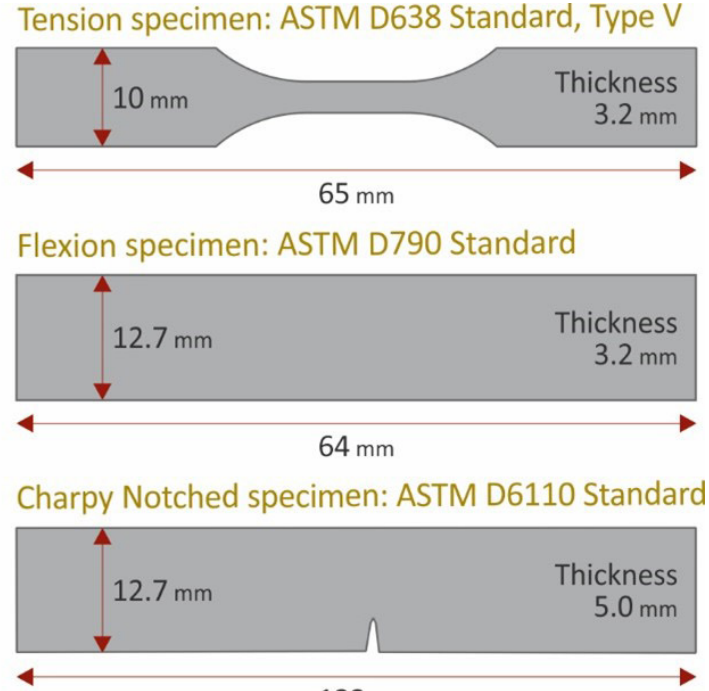

$122 \mathrm{~mm}$

Figure 2. Fundamental SLA 3D printing settings, specimens' dimensions, and images from 3D printed specimens. 


\subsection{Mechanical Performance Testing}

Tensile, flexural, impact, and Vickers microhardness measurements were performed to evaluate the mechanical performance of the studied materials. The tensile properties were studied according to the ASTM D638-02a international standard on five (5) type V specimens of $3.2 \mathrm{~mm}$ thickness. For this purpose, an Imada MX2 (Imada Inc., Northbrook, IL, USA) machine equipped with standardized grips was used. The tension speed was set to $10 \mathrm{~mm} / \mathrm{min}$, while the tests were conducted in room conditions $\left(21^{\circ} \mathrm{C}, 50 \% \mathrm{RH}\right)$. The Imada MX2 machine was also used for the flexural tests. The grips were replaced with the flexural setup of three-point bending (with $52 \mathrm{~mm}$ span), following the ASTM D790-10 international standard. For the flexural test, five specimens of $3.2 \mathrm{~mm}$ thickness were evaluated. The remaining specimens' dimensions are shown in Figure 2. Charpy's notched specimens impact tests were conducted according to ASTM D6110-04 international standard. Five (5) specimens were assessed using a Terco MT220 machine (Terco AB, Huddinge, Sweden). Randomly selected specimens were used for Vickers microhardness measurements according to the ASTM E384-17 international standard, which was followed. Five (5) measurements were taken on each case.

\subsection{Morphological, Thermal, and Antibacterial Analysis}

To investigate the processing efficiency, Scanning Electron Microscopy (SEM) analysis was conducted on the fractal and side surfaces of 3D printed tensile specimens. A JEOL 6362LV (Jeol Ltd., Norwood, MA, USA) apparatus was used for this purpose, while images were taken on two (2) magnification levels. Samples were randomly selected and first sputter-coated with gold $(\mathrm{Au})$ to avoid charging effects. The electron microscope was set in the high vacuum mode at $20 \mathrm{kV}$ acceleration voltage. The same apparatus was used for energy-dispersive $\mathrm{X}$-ray spectroscopy (EDS) analysis on uncoated specimens to verify the main elements in each material.

Atomic Force Microscopy (AFM) was used to investigate specimens' surface morphology and roughness in the micro-scale. A microscope solver P47H Pro (NT-MDT, Moscow, Russia) apparatus was used for this purpose. Commercially available silicon cantilevers with a scanning frequency of $1 \mathrm{~Hz}$, cantilever spring constant of $35 \mathrm{~N} / \mathrm{m}$, tip cone angle of $20^{\circ}$, and tip radius of $10 \mathrm{~nm}$ were used at a resonant frequency of $300 \mathrm{kHz}$. Samples of approximately $10 \mathrm{mg}$ from the specimens were also assessed for their thermal behavior by thermogravimetric analysis (TGA). A Perkin Elmer Diamond TGA/DTGA (Perkin Elmer Inc., Waltham MA, USA) apparatus was used, and measurements were taken at a temperature range from $40^{\circ} \mathrm{C}$ to $550{ }^{\circ} \mathrm{C}$. The temperature ramp was set at $10^{\circ} \mathrm{C} / \mathrm{min}$.

The antibacterial activity of the fabricated nanocomposites was investigated using the agar well diffusion method. Tests were conducted in a microbiological laboratory for two (2) different bacteria. Gram-negative Escherichia coli (E. coli) and gram-positive Staphylococcus aureus (S. aureus) were cultivated in $85 \mathrm{~mm}$ diameter Petri dishes. The tested cylindrical specimens were $3 \mathrm{D}$ printed according to the specifications shown in Figure 2, and their dimensions were $12.7 \mathrm{~mm}$ in diameter and $5.00 \mathrm{~mm}$ in height. Petri dishes were placed in an oven at $37^{\circ} \mathrm{C}$ for a period of $24 \mathrm{~h}$ targeting the optimized diffusion of the antimicrobial agents in the agar and inhibiting the germination and growth of the test microorganism. Subsequently, the inhibition zones developed peripherally of the 3D printed specimens were measured using optical equipment.

\section{Results}

\subsection{Mechanical Performance Analysis}

The tensile test results are shown in Figure 3. Figure 3a presents a typical curve of tensile stress $(\mathrm{MPa})$ versus strain $(\mathrm{mm} / \mathrm{mm})$ for each tested nanocomposite. The introduction of $\mathrm{Cu}$ nanoparticles in low rations has a clear effect on the ductility of the nanocomposites. The ductile behavior of copper affected the brittle behavior of the SC resin for all cases studied, except SC Cu $2.0 \mathrm{wt}$.\%. Such a change can be attributed to saturation effects or low-quality polymerization processing, due to the increased filler loading. Figure $3 b, c$ 
show the tensile stress at break (MPa) and tensile modulus of elasticity (MPa) to filler ratio (wt.\%). Figures showed an enhancement effect from the introduction of $\mathrm{Cu}$ nanoparticles in the SC Cu 0.5 and $1.0 \mathrm{wt}$ \% nanocomposites, while a similar degradation effect is shown for the SC Cu $2.0 \mathrm{wt}$ \%, which is consistent with the stress to strain curves of Figure 3a.
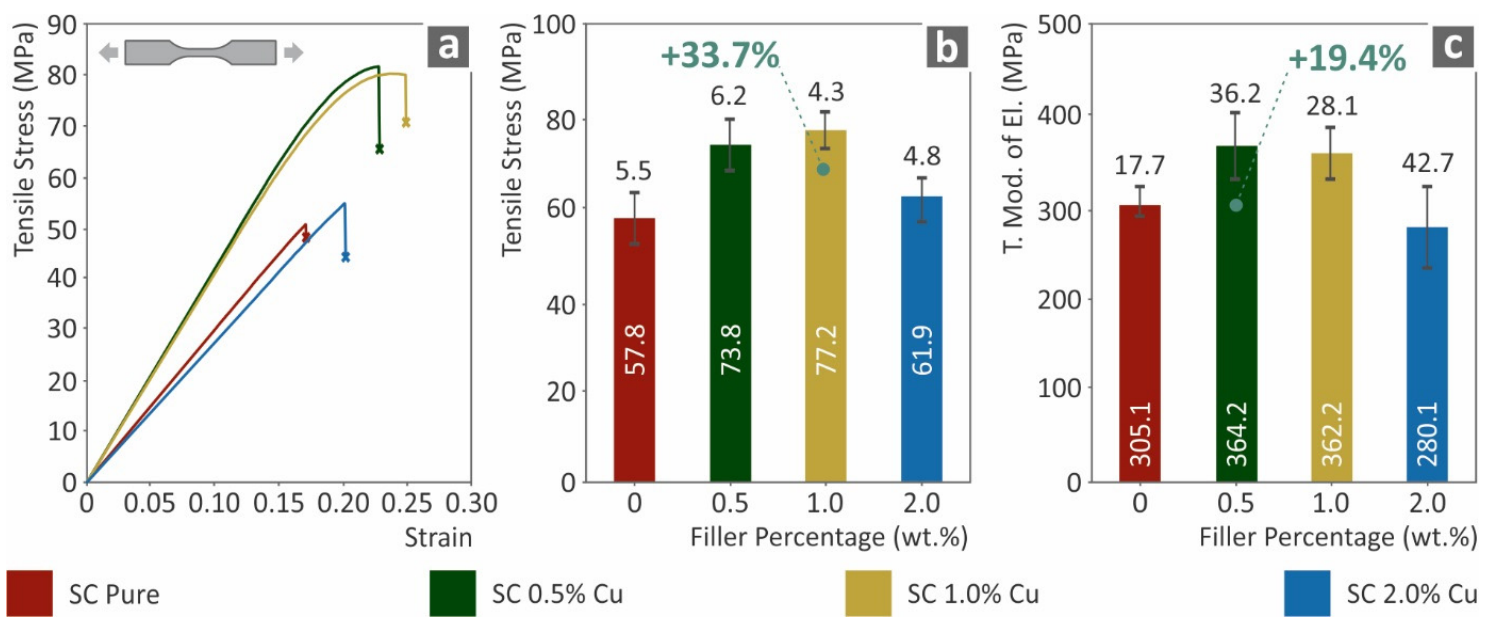

Figure 3. (a) Typical tensile stress (MPa) to strain $(\mathrm{mm} / \mathrm{mm})$ curves, $(\mathbf{b})$ tensile stress at break (MPa) to filler loading (wt.\%), (c) tensile elastic modulus (MPa) to filler ratio (wt.\%).

The flexural test results are shown in Figure 4. As shown in Figure $4 b, c$, both the flexural strength (MPa) at 5.0\% strain and the flexural modulus of elasticity were significantly increased compared to those of the pure SC material, which is consistent with the tensile test results. SC Cu $1.0 \mathrm{wt}$.\% nanocomposite presented the highest flexural performance among the cases studied and especially a $33.4 \%$ increase was measured at the flexural stress and a $20.3 \%$ increase at the flexural modulus of elasticity. SC Cu $2.0 \mathrm{wt} . \%$ nanocomposite presented vigorous degraded flexural strength and modulus of elasticity, which also agrees with the tensile test results. Filling ratios higher than $1.0 \mathrm{wt} . \%$ enabled plausible agglomerations in the nanocomposite, which could plausibly deteriorate mechanical performance. Additionally, this degradation in the mechanical performance at higher loadings could also be attributed to low polymerization of the material, due to the high concentration of copper, which could enhance the diffusion effect during 3D printing.
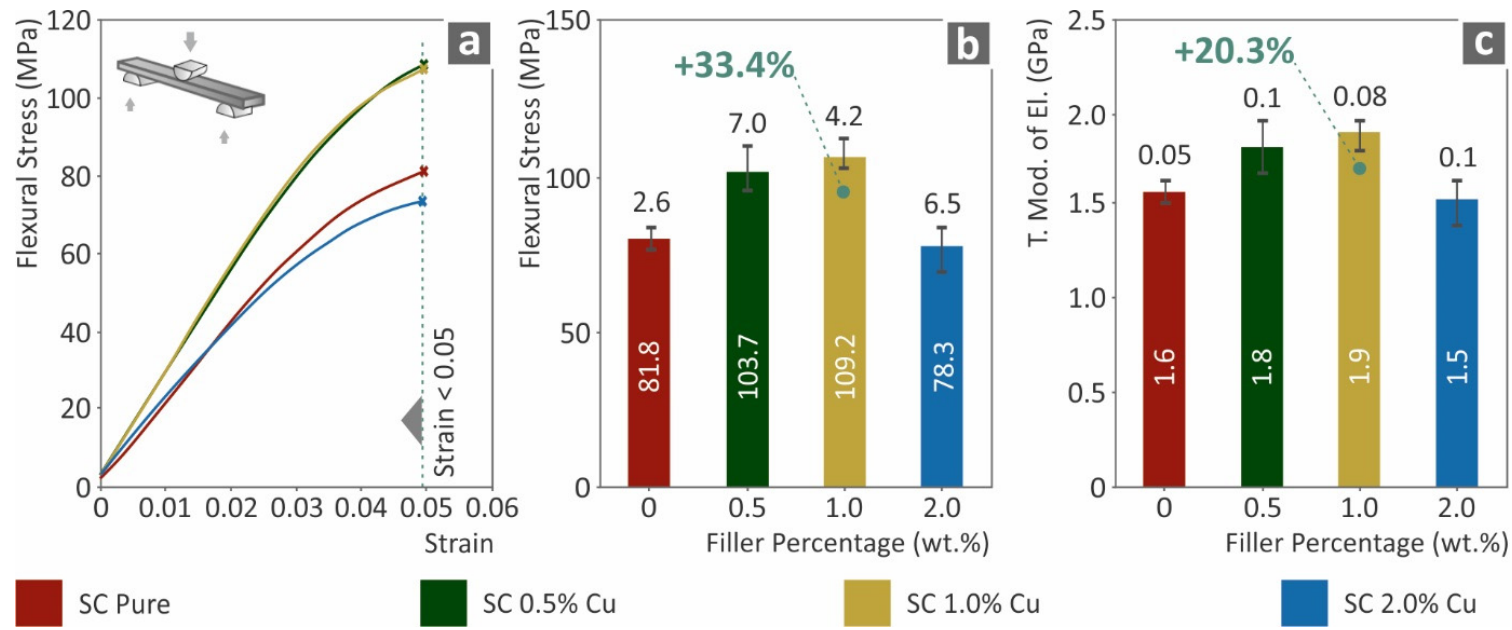

Figure 4. (a) Typical flexural stress (MPa) to strain $(\mathrm{mm} / \mathrm{mm})$ curve, (b) Flexural stress (MPa) at 5.0\% strain (following the standard instructions) to filler loading (wt.\%), (c) flexural elastic modulus (MPa) to filler ratio (wt.\%). 
Figure 5 shows the results for the tensile toughness $\left(\mathrm{MJ} / \mathrm{m}^{3}\right)$ and the corresponding flexural toughness $\left(\mathrm{MJ} / \mathrm{m}^{3}\right)$. These measures were calculated as an integral of the corresponding stress-strain curves of all the tested specimens, and the average values are presented below. Such toughness calculations show a generic view of the absorbed energy during the tests. Following the tensile and flexural performances, the corresponding toughness of the nanocomposites assessed was enhanced in the case of SC Cu $1.0 \mathrm{wt} . \%$ nanocomposite. An increase of $68.5 \%$ was calculated for tensile toughness in comparison to the neat SC material, while the same material absorbed 34.2\% more flexural energy in comparison to pure SC materials. Increasing the filler ratio over $1.0 \mathrm{wt} . \%$ showed a decrease either in tensile or in flexural properties. Such a decrease could plausibly occur owing to low polymerization effects. Plausible agglomerations could also introduce such behavior. These phenomena are more thoroughly analyzed in the discussion section of this work.
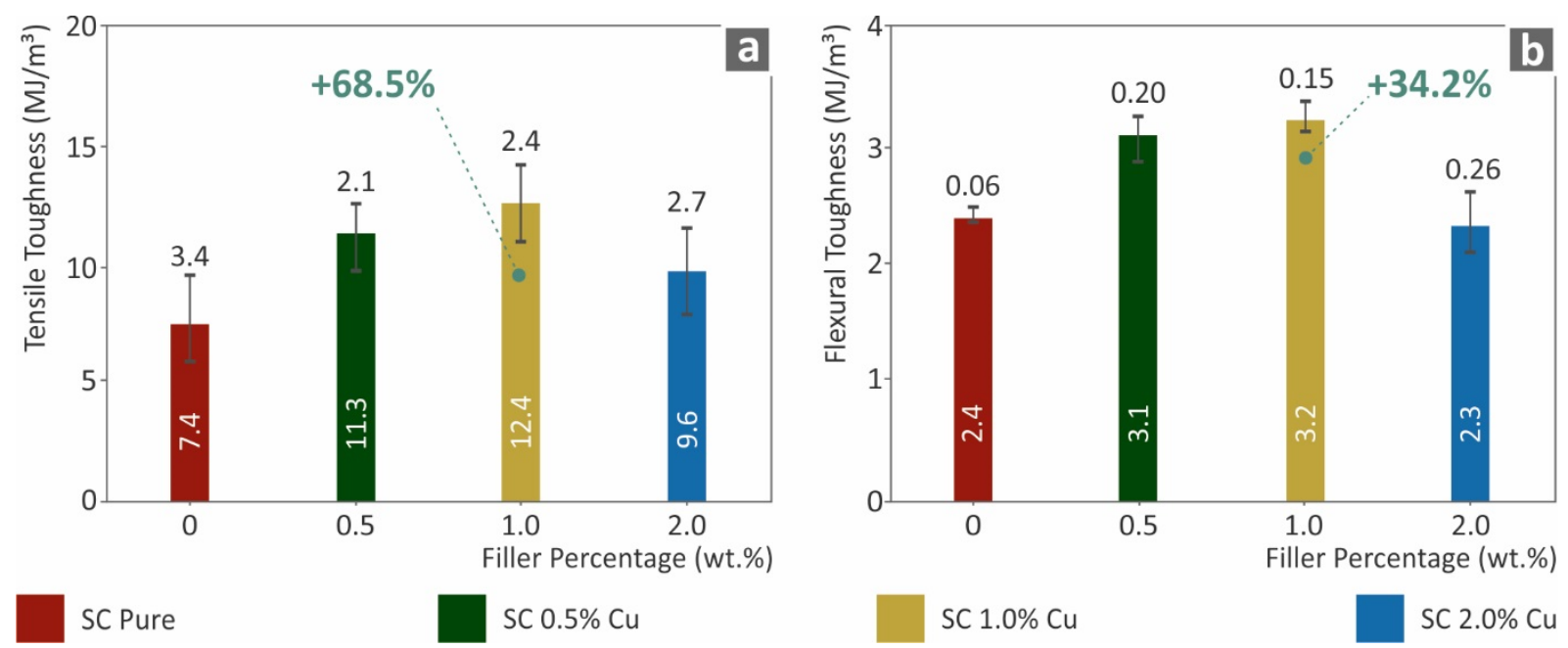

Figure 5. (a) Average tensile toughness $\left(\mathrm{MJ} / \mathrm{m}^{3}\right)$ to filler loading (wt.\%), (b) Average flexural toughness $\left(\mathrm{MJ} / \mathrm{m}^{3}\right)$ to filler ratios $(\mathrm{wt} . \%)$.

The mechanical performance analysis was also investigated with Charpy notched impact tests and Vickers microhardness measurements, the results of which are presented in Figure 6. In agreement with the other mechanical tests of this work, the impact toughness increased by approximately $30 \%$ for SC Cu $1.0 \mathrm{wt} . \%$ nanocomposite in comparison to pure SC resin. The ductile behavior of the $\mathrm{Cu}$ nanoparticles enabled the fabrication of nanocomposites that absorb higher energy levels, which increased the impact strength on the specimens. Similar performance was seen for the microhardness of the surfaces, which was approximately $25 \%$ higher than that of the neat material. In general, the mechanical performance results were in good agreement. Lower filler loadings ( $0.5 \mathrm{wt} . \%$ and $1.0 \mathrm{wt} . \%)$ showed an increasing effect, while the highest SC Cu $2.0 \mathrm{wt} . \%$ nanocomposite had the lowest performance in all mechanical tests conducted. 

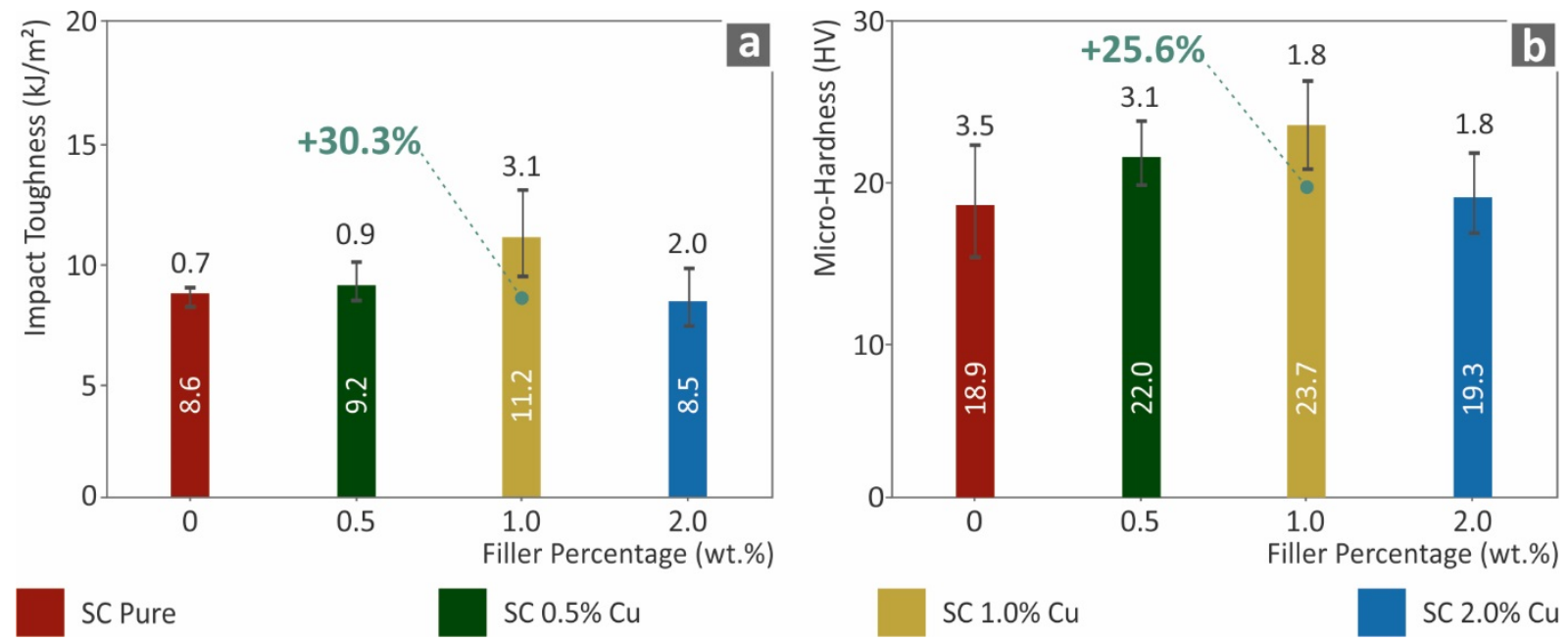

Figure 6. (a) Charpy's notched impact toughness $\left(\mathrm{kJ} / \mathrm{m}^{2}\right)$ to filler loadings (wt.\%), (b) Vickers microhardness (HV) to filler ratios (wt.\%).

\subsection{Thermal, Morphological, and Antibacterial Analysis}

\subsubsection{Thermal Analysis}

The TGA results are shown in Figure 7. Specifically, in Figure 7A, the weight (\%) of each nanocomposite to temperature $\left({ }^{\circ} \mathrm{C}\right)$ is presented, while in Figure $7 \mathrm{~B}$, the weight loss rate is presented in comparison to the corresponding temperature. The remaining nanocomposites were in good agreement with the corresponding filling ratios. Considering the effect of copper, which reduced the mass reduction rate, as expected, it could be assumed that the mixing procedure was of good quality. In agreement with the results of other tests, the SC Cu $2.0 \mathrm{wt} . \%$ nanocomposite showed vigorous degradation. As the effect of copper nanoparticles could not be responsible for such performance, a plausible implication of low-quality polymerization could be assumed through the TGA graphs.
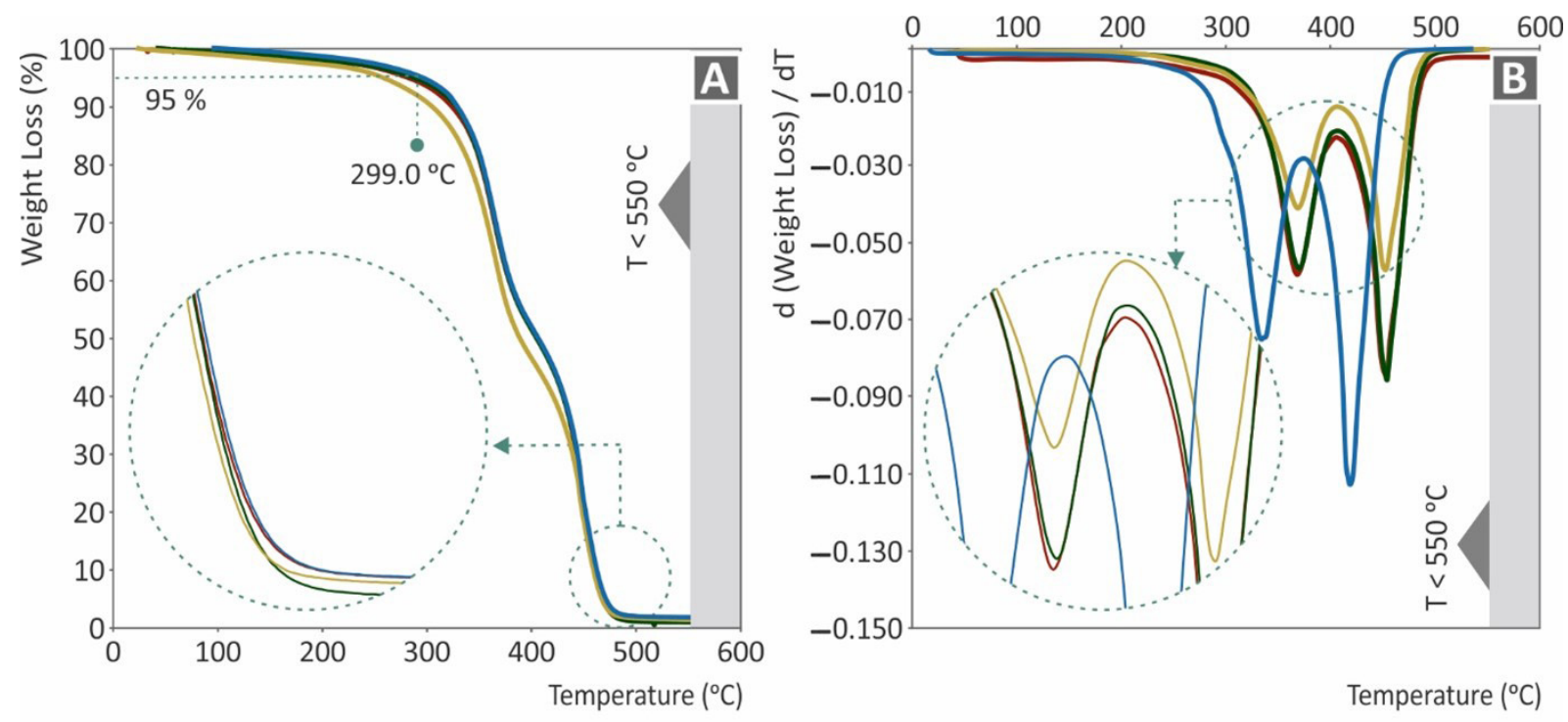

Figure 7. (A) Sample's weight $(\%)$ to temperature $\left({ }^{\circ} \mathrm{C}\right),(\mathbf{B})$ weight loss rate $(\mathrm{mg} / \mathrm{mg})$ to temperature $\left({ }^{\circ} \mathrm{C}\right)$. 


\subsubsection{Morphological Analysis}

Figure 8 shows the side surfaces of tensile specimens for all studied materials. $30 \times$ magnification level images verified the 3D printing specifications. Specifically, neat SC and SC Cu $0.5 \mathrm{wt} . \%$ materials have a smooth surface, indicating a fine interlayer fusion. A similar view is also shown for SC Cu $1.0 \mathrm{wt} . \%$ nanocomposite. Fusion is in fine agreement with minor differences which could plausibly imply slight agglomerations. In the case of SC Cu $2.0 \mathrm{wt}$.\% nanocomposite, dimensional accuracy of layering shows a rather fine quality, while the slightly more intense visible layers could assume lower interlayer fusion. As per SLA technology, due to the operating principle, interlayer and intralayer fusion quality depend on the polymerization process quality. Thus, a low-quality polymerization assumption could plausibly be assumed for high filling loadings. Figure $8 \mathrm{a}, \mathrm{b}$, showing the side surface of tensile specimens built with pure resin show a smoother external surface of the specimens, typical for this type of manufacturing process, attributed to proper polymerization and correct 3D printing settings. With the addition of $0.5 \mathrm{wt} . \%$ filler (Figure $8 \mathrm{c}, \mathrm{d}$ ), a similar surface pattern appears, but with abnormalities, in this case, attributed to low polymerization of the material during the process. Increasing further the filler loading to $1 \mathrm{wt} . \%$ (Figure 8e,f) the pattern of the side surface changes. The abnormalities are reduced, and the build layers are more clearly visible. At the highest filler loading tested in this work (Figure $8 \mathrm{f}, \mathrm{h}-2 \mathrm{wt} . \%$ ), specimens' side surface built-quality seems to be reduced, when compared to lower filler loadings.

Figure 9 shows the fractal areas of tensile specimens for all studied materials. The lower magnification images of the tensile specimens' fracture area provided sufficient information on the fracture mechanism. In particular, the introduction of $\mathrm{Cu}$ nanoparticles enabled a more ductile performance on the fabricated nanocomposites, which is observed at the fracture surfaces. The sudden brittle break of the neat SC specimen can be attributed to the sharp surface presented in the corresponding image (Figure 9A). Nanocomposites with filler loading of 0.5 and $1.0 \mathrm{wt} . \%$ showed a smaller region that failed in a brittle way, which can be observed at the start of the fracture arrows shown in the figure. The remaining specimen's area shows a more ductile fracture mechanism, which is in good agreement with the corresponding mechanical analysis. In higher-magnification images, the ductile behavior is visible, while significant agglomerations cannot be seen. 

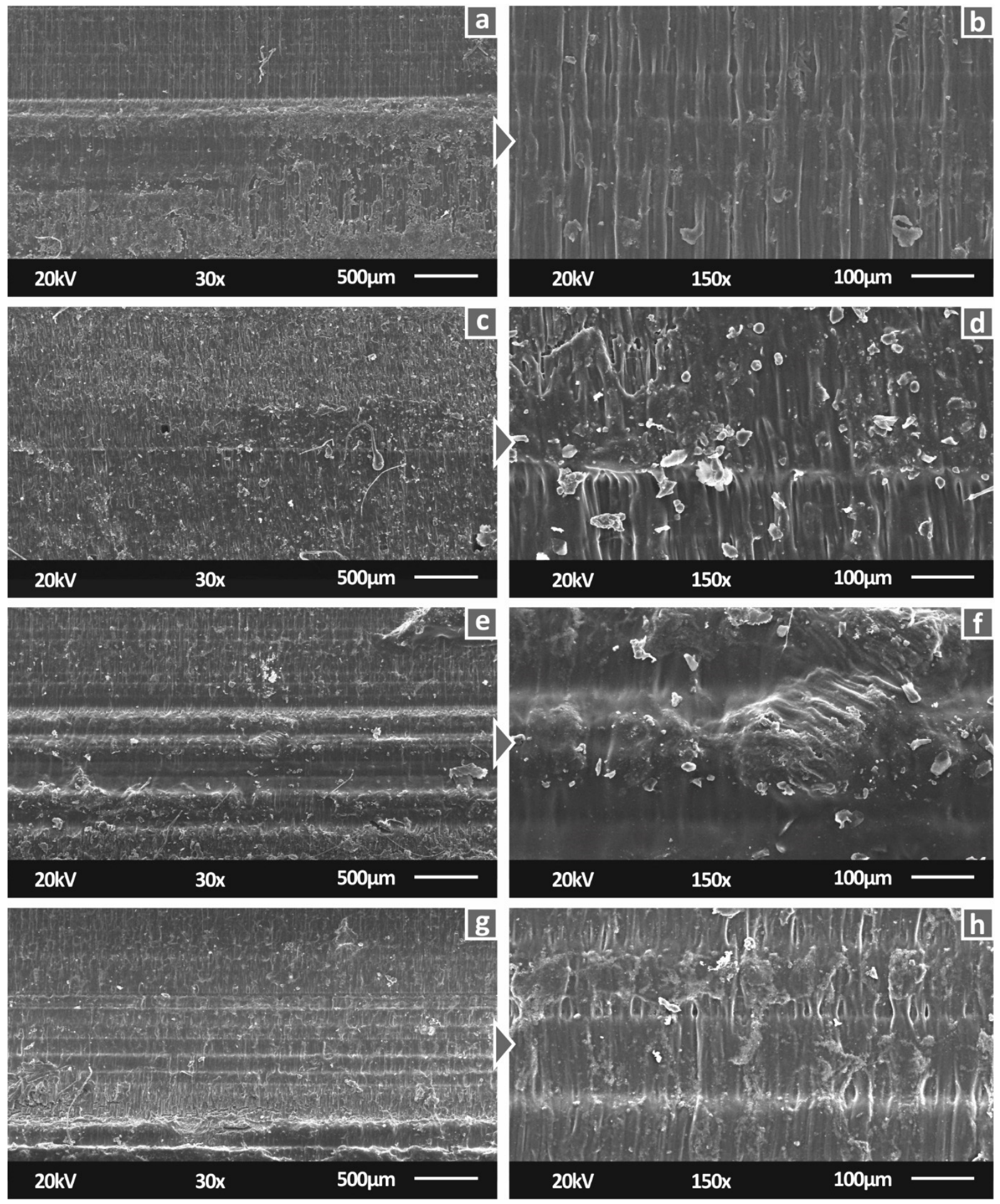

Figure 8. Side surface of tensile specimens in 30× magnification for (a) Pure SC, (c) SC Cu 0.5 wt.\%, (e) SC Cu 1.0 wt.\%, (g) SC Cu 2.0 wt.\%, same surfaces in 150× magnification for (b) Pure SC, (d) SC Cu 0.5 wt.\%, (f) SC Cu 1.0 wt.\%, (h) SC Cu 2.0 wt. \%. 

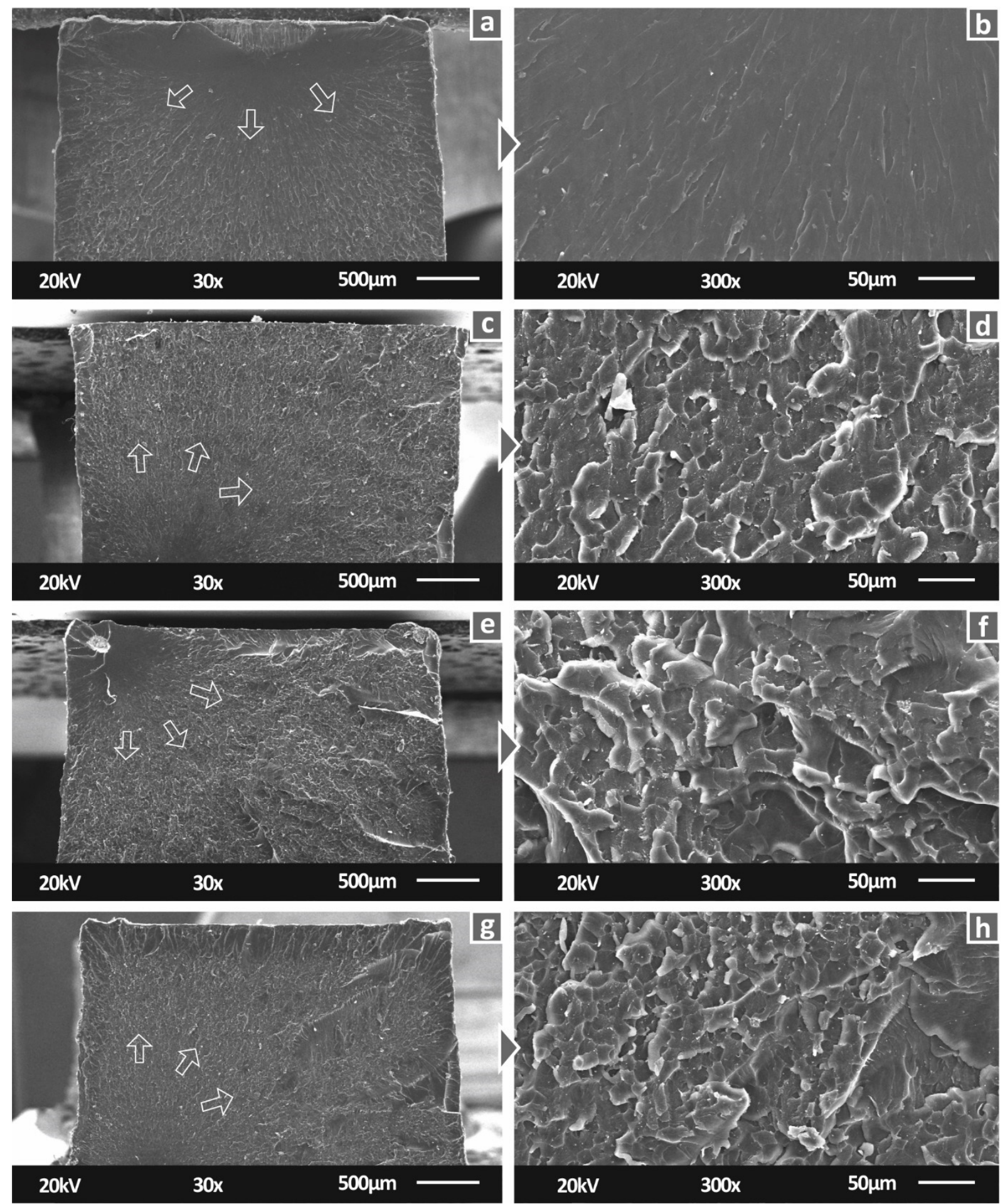

Figure 9. Fracture surface of tensile specimens in 30× magnification for (a) Pure SC, (c) SC Cu 0.5 wt.\%, (e) SC Cu 1.0 wt.\%, (g) SC Cu 2.0 wt.\%, same surfaces in 300× magnification for (b) Pure SC, (d) SC Cu 0.5 wt. $\%$, (f) SC Cu $1.0 \mathrm{wt} \%$, (h) SC Cu $2.0 \mathrm{wt} . \%$. Arrows in the pictures show the fracture evolution in the section.

Higher magnification images were taken in the fractal area (Figure 10a-c). At the highest magnification level, slight agglomerations were observed, which did not create any processing problems, although the implications of the reduced polymerization quality at higher loadings still exist. EDS analysis (Figure 10d-f) verified the presence of copper in 
the materials, and graph peaks reveal an indication of good dispersion of the filler in the matrix material.
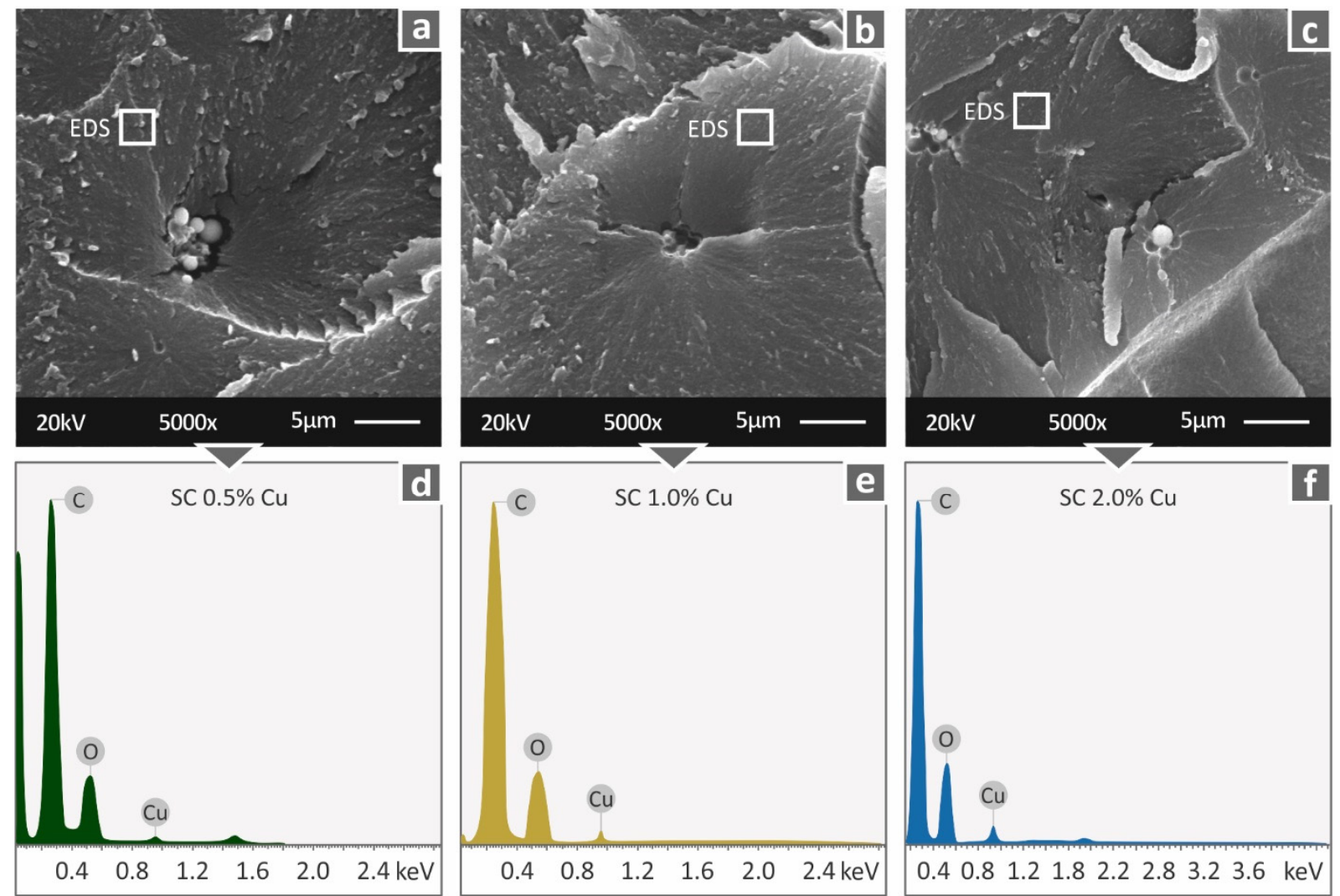

SC $0.5 \% \mathrm{Cu}$

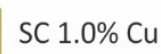

SC $2.0 \% \mathrm{Cu}$

Figure 10. Fracture area high magnification captures at 5000× level (a) SC Cu 0.5 wt.\%, (b) SC Cu 1.0 wt.\%, (c) SC Cu 2.0 wt.\% and the corresponding EDS analysis results (d) SC Cu 0.5 wt.\%, (e) SC Cu $1.0 \mathrm{wt} . \%$, (f) SC Cu $2.0 \mathrm{wt} . \%$. White squares indicate the areas for EDS analysis.

Finally, through AFM analysis of the cured 3D printed specimens' surfaces, their morphology is further investigated. Figure 11 presents three-dimensional images of the specimen surfaces captured with AFM, along with the corresponding average calculated roughness of each studied nanocomposite. The increase of the filler, as expected, further enhances the deterioration of the surface quality. 

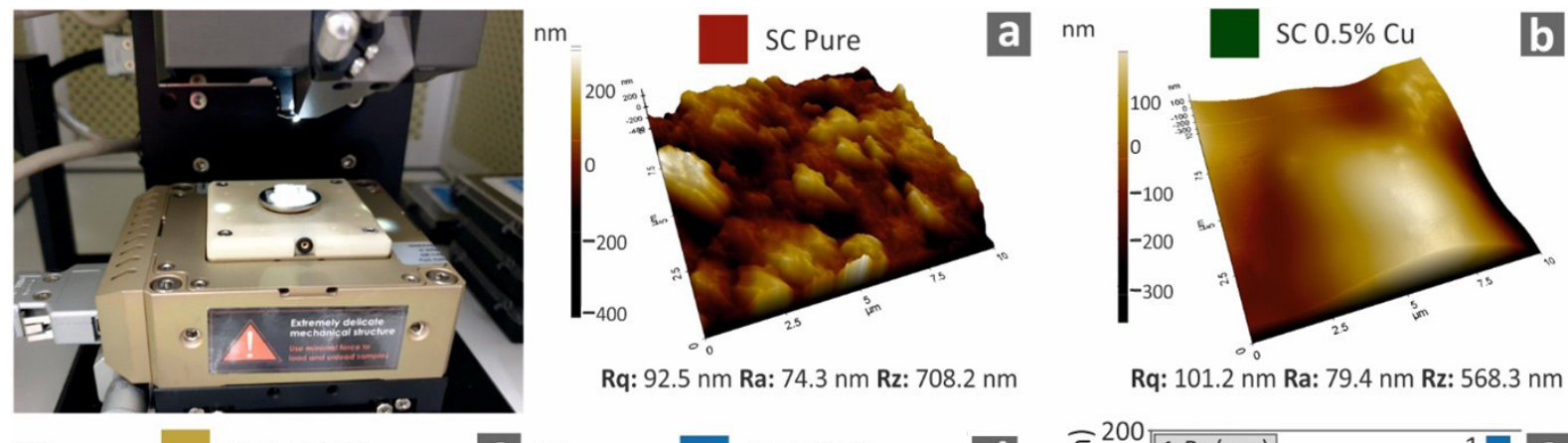

Rq: 92.5 nm Ra: 74.3 nm Rz: 708.2 nm

Rq: 101.2 nm Ra: 79.4 nm Rz: 568.3 nm
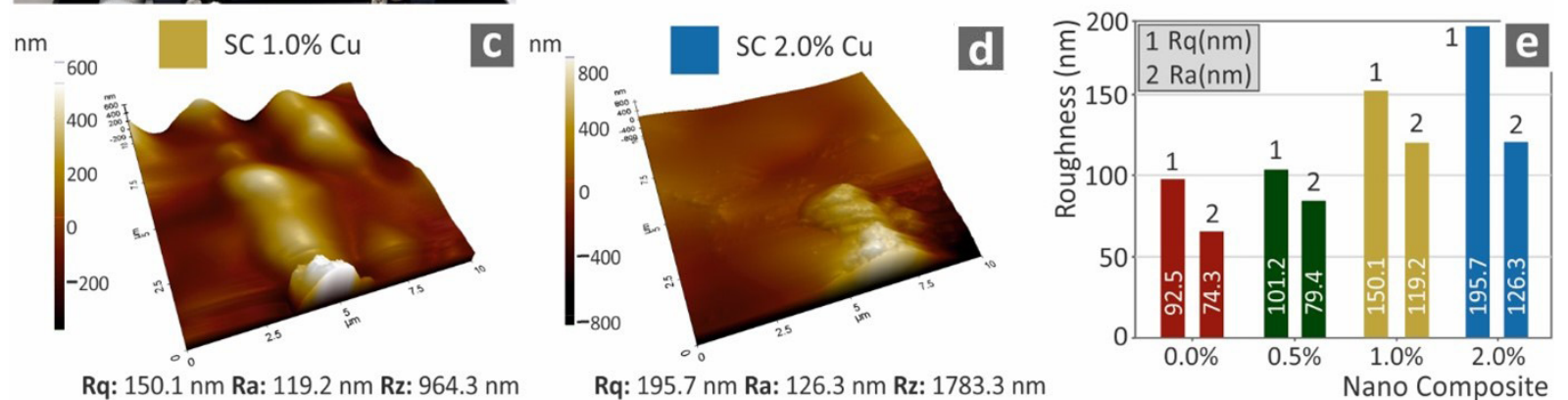

Rq: $150.1 \mathrm{~nm}$ Ra: $119.2 \mathrm{~nm} \mathrm{Rz:} 964.3 \mathrm{~nm}$

Rq: 195.7 nm Ra: 126.3 nm Rz: 1783.3 nm

Figure 11. Three-dimensional graphical presentation of the measured with AFM surfaces of 3D printed specimens for all the tested materials (a-d), (e) measured roughness (nm) to filler ratio (wt.\%).

\subsubsection{Antibacterial Analysis}

In this work, to imitate the biocidal properties of HDPs, copper nanoparticles were used as fillers in commercial SLA resin. While lower filler ratios could not provide results with clearly visible antibacterial performance with the method employed in this work, the SC Cu $2.0 \mathrm{wt}$.\% showed an intense inhibition zone, which was measured approximately $4.5 \mathrm{~mm}$ wide. A narrow inhibition zone was observed for the nanocomposite with 1.0 wt. $\%$, while 0.5 wt. $\%$ could not provide visible antibacterial activity for gram-negative $E$. Coli bacteria. Images acquired after $24 \mathrm{~h}$ of cultivation of $E$. coli for each tested material are shown in Figure 12. Similar behavior was also observed for gram-positive S. aureus bacteria, as shown in Figure 13. In this case, the nanocomposites filled with $1.0 \mathrm{wt} . \%$ and $2.0 \mathrm{wt} . \%$ created a similar inhibition zone of approximately $5.5 \mathrm{~mm}$. Correspondingly, the neat SC and SC Cu $0.5 \mathrm{wt} . \%$ nanocomposite did not show antibacterial activity for S. aureus bacterium. The filler ratio for introducing antibacterial performance on the specific nanocomposites exhibits a threshold of $1.0 \mathrm{wt} . \%$ loading as per the two (2) assessed bacteria. In lower ratios, $\mathrm{Cu}$ concentration on the specimens' surface is not adequate to repel bacterial growth. 

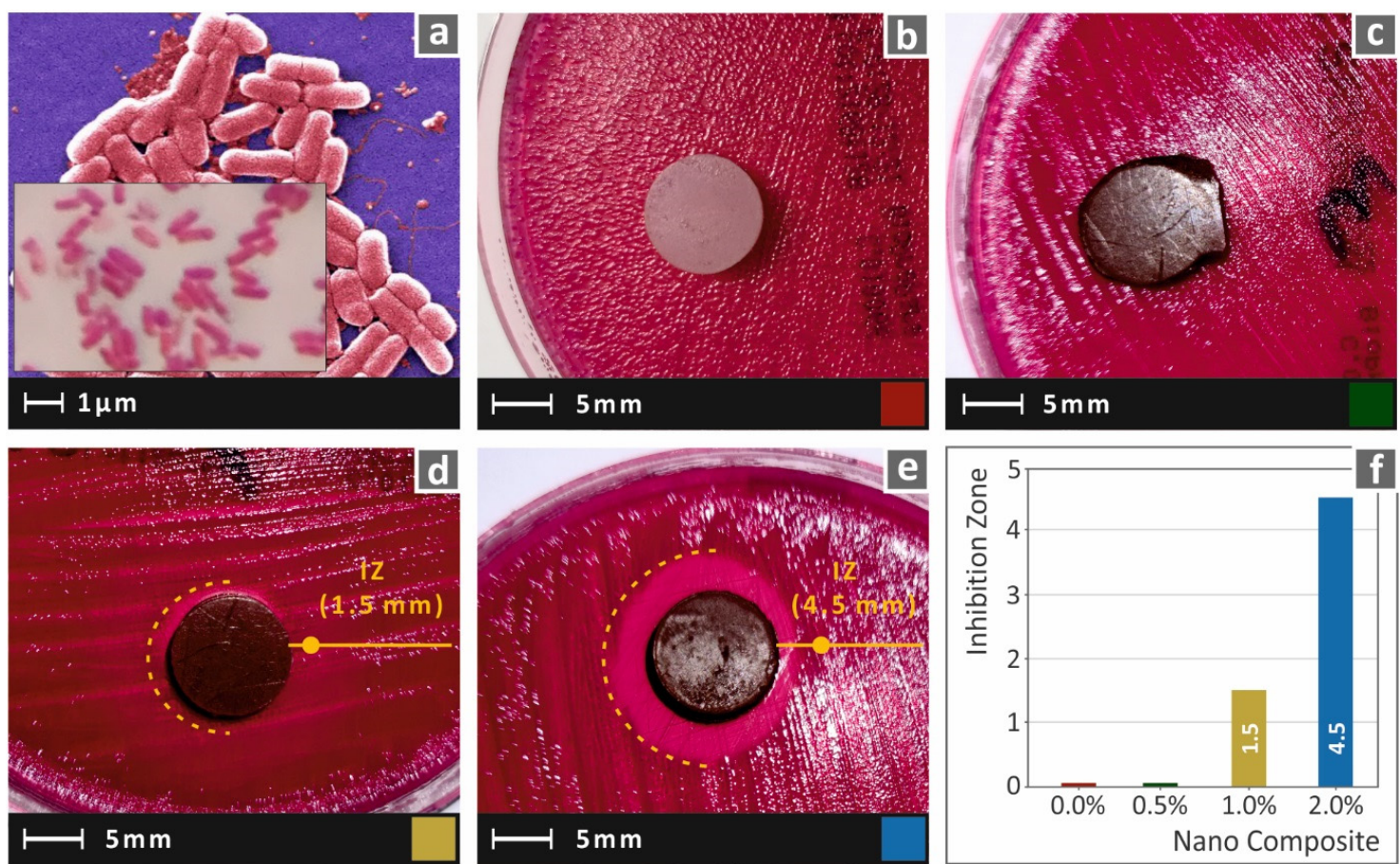

SC Pure

$\mathrm{SC} 0.5 \% \mathrm{Cu}$

SC $1.0 \% \mathrm{Cu}$

SC $2.0 \% \mathrm{Cu}$

Figure 12. (a) typical E. Coli morphology, (b-e) Vertical captures after $24 \mathrm{~h}$ cultivation of tested specimen in Petri dish for each corresponding tested material, (f) Comparative graph of the measured inhibition zones to filler loading (wt.\%).
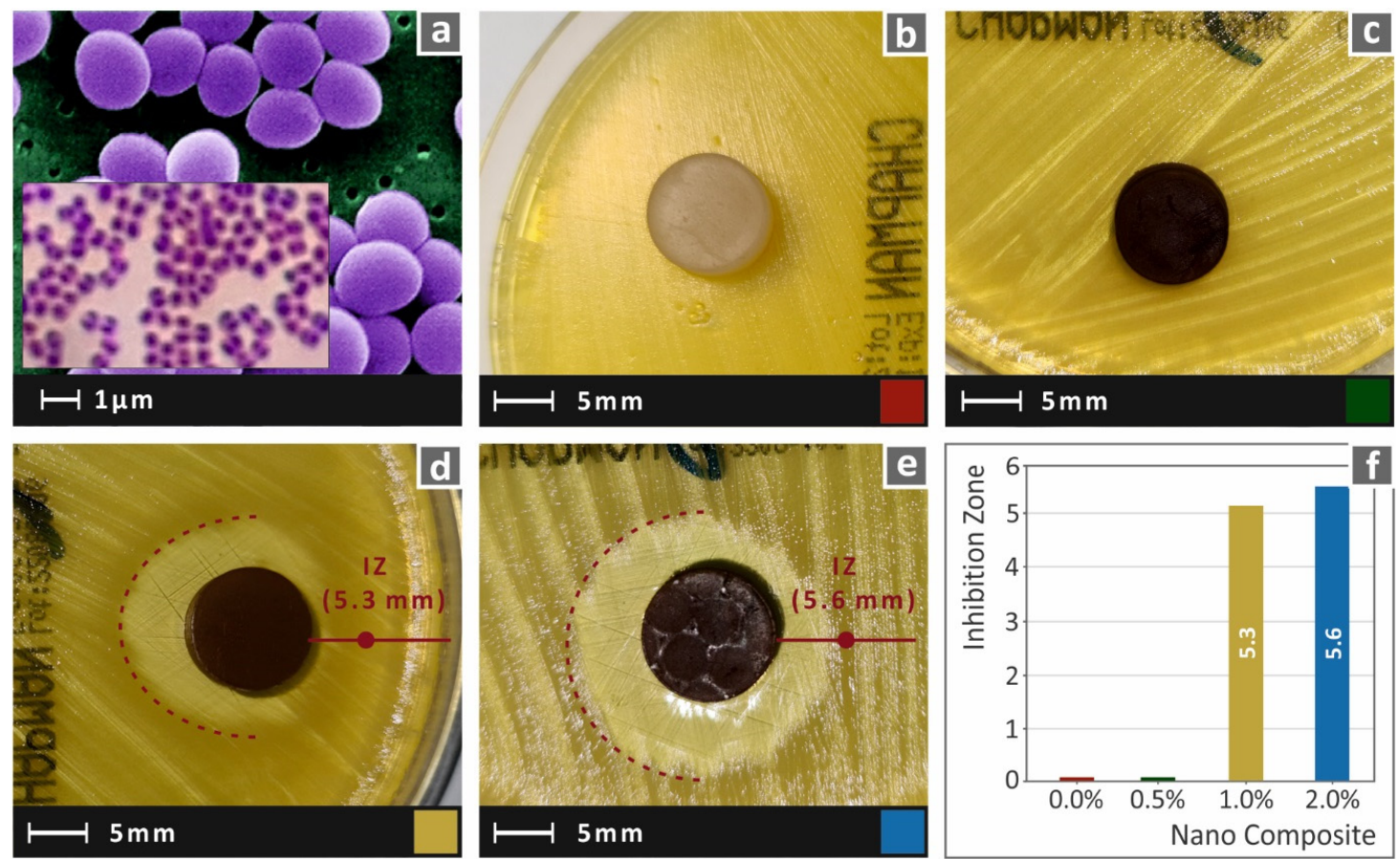

SC Pure

$\mathrm{SC} 0.5 \% \mathrm{Cu}$

SC $1.0 \% \mathrm{Cu}$

SC $2.0 \% \mathrm{Cu}$

Figure 13. (a) typical S. Aureus morphology, (b-e) Vertical captures after $24 \mathrm{~h}$ cultivation of tested specimen in Petri dish for each corresponding tested material, (f) Comparative graph of the measured inhibition zones to filler loading (wt.\%). 


\section{Discussion}

In this study, a common resin for the SLA process was used as a matrix material for the development of nanocomposites mimicking HDPs' biocidal properties. To achieve that, copper, in nanoparticles form, was used as filler in various concentrations. The nanocomposites developed showed at the same time enhanced mechanical response when compared with the matrix material. All mechanical tests conducted in this work, i.e., tensile, flexural, and impact tests, showed a similar trend in the results on the effect of $\mathrm{Cu}$ nanoparticles on the matrix material. $\mathrm{Cu}$ nanoparticles showed an enhanced mechanical performance up to filling ratios of $1.0 \mathrm{wt}$ \%, while degradation occurred over such filler ratios. The morphological analysis provided significant feedback on the processing quality and confirmed the increase of the ductile behavior of the fabricated nanocomposites, while it revealed valuable information for the fracture mechanism on the tensile specimens. The antibacterial activity of the nanocomposites was adequate at higher filler ratios, while the threshold for mechanical performance enhancement was lower, with the 1.0 wt.\% nanocomposite depicting both enhanced mechanical response and antibacterial activity.

The $2.0 \mathrm{wt}$.\% filler ratio implicated plausible agglomeration effects, which may have deteriorated the total performance of the material, as its results were comparable with neat SC. The laser spot size of the utilized 3D printer is 85 microns diameter, and a local agglomeration with a size smaller than 10 microns could diffuse the laser beam. Such an effect could provide low-quality polymerization locally in the interface area of the nanoparticles with the matrix material. This plausible low-quality polymerization enables the possibility of lower fusion in either the intra- or interlayer direction. Even in the SC Cu 1.0 wt.\% nanocomposite, minor agglomerations were seen, although the mechanical performance was significantly enhanced. In this case, it could be assumed that the agglomeration size, which is affected by the filler ratio, is important for the polymerization process, the interface quality of the nanoparticles, and the matrix material. Further studies could provide more information about the mechanisms and exact threshold points.

The antibacterial performance results, in combination with the corresponding mechanical performance results, generally indicate a high potential for SLA UV-cured resin $\mathrm{Cu}$ nanocomposites. It was found that the $1.0 \mathrm{wt}$ \% loading is sufficient composite material. Such nanocomposites can be easily processed in SLA 3D printers, and the fabrication procedure could be implemented without high-end technology mixing equipment. Similar behavior was also observed for the SC Cu $0.5 \mathrm{wt}$ \%, which further enables a prospect for a more in-depth analysis for the threshold, to fabricate resin $\mathrm{Cu}$ nanocomposites with enhanced mechanical performance and antibacterial activity. Such optimized nanocomposites can be used in SLA technology for high-end medical applications.

\section{Conclusions}

In this study, an attempt was made to develop SLA 3D printing materials mimicking the biocidal properties of the HDPs, through an affordable process, using a common lowcost commercial resin suitable for this use. Nanocomposites were developed at various concentrations and their antibacterial performance was investigated using the agar well diffusion method for gram-negative E. coli and gram-positive $S$. aureus bacteria. The results show high potential for the introduction of $\mathrm{Cu}$ nanoparticles in UV-cured resins in SLA implementations. Cu nanoparticles enhanced the mechanical performance of the nanocomposites, while such an enhancement was conducted with low filler ratios of 0.5 and $1.0 \mathrm{wt} . \%$. Additionally, antibacterial activity was found at higher filler ratios, which further confirmed the great potential of the fabricated materials.

Considering the previously mentioned results, in combination with the processing followed during the current study, it should be mentioned that innovative solutions could be prepared, using commonly used equipment. SLA 3D printing, enabling the manufacturing of high-complexity geometries, along with the enhanced nanocomposite properties, is a strong combination for exploitation in medical implementations. Furthermore, the recent pandemic has led to problems in the existing supply chain systems, which are vulnerable 
in emergencies and 3D printing can also be exploited in such situations. SLA UV-cured resin $\mathrm{Cu}$ nanocomposites were evaluated as key materials, as their fabrication could be implemented in local laboratories, and the 3D printed parts could provide solutions to problems locally. The materials produced in this work could further exploit 3D printing usage during the present pandemic in medical- and engineering-related fields which require materials with antibacterial performance and enhanced mechanical response, such as the materials developed in this work. As future work, the antibacterial performance could be further investigated with more advanced methods and the mechanical and antibacterial performance loading threshold could be further optimized by statistical analysis tools and modeling, which were not among the purposes of the current study.

Author Contributions: Conceptualization, N.V. and E.V.; methodology, M.P.; software, N.M., A.G. and S.K.; validation, N.V., S.K., A.G. and M.P.; formal analysis, M.P. and A.G.; investigation, E.V. and S.K.; resources, N.V. and D.T.; data curation, N.M. and D.T.; writing-original draft preparation, E.V.; writing, review, and editing, M.P.; visualization, N.V., N.M. and D.T.; supervision, N.V.; project administration, M.P.; funding acquisition, N.V. All authors have read and agreed to the published version of the manuscript.

Funding: This study received no external funding.

Data Availability Statement: The data presented in this study are available upon request from the corresponding author.

Acknowledgments: The authors would like to thank Aleka Manousaki from the Institute of Electronic Structure and Laser of the Foundation for Research and Technology, Hellas (IESL-FORTH), for obtaining the SEM images presented in this work.

Conflicts of Interest: The authors declare no conflict of interest.

\section{References}

1. Raffi, M.; Mehrwan, S.; Bhatti, T.M.; Akhter, J.I.; Hameed, A.; Yawar, W.; Ul Hasan, M.M. Investigations into the antibacterial behavior of copper nanoparticles against Escherichia coli. Ann. Microbiol. 2010, 60, 75-80. [CrossRef]

2. Ergene, C.; Yasuhara, K.; Palermo, E.F. Biomimetic antimicrobial polymers: Recent advances in molecular design. Polym. Chem. 2018, 9, 2407-2427. [CrossRef]

3. Slavin, Y.N.; Asnis, J.; Häfeli, U.O.; Bach, H. Metal nanoparticles: Understanding the mechanisms behind antibacterial activity. J. Nanobiotechnol. 2017, 15, 1-20. [CrossRef]

4. Chatterjee, A.K.; Chakraborty, R.; Basu, T. Mechanism of antibacterial activity of copper nanoparticles. Nanotechnology 2014, 25. [CrossRef]

5. Dilberoglu, U.M.; Gharehpapagh, B.; Yaman, U.; Dolen, M. The Role of Additive Manufacturing in the Era of Industry 4.0. Procedia Manuf. 2017, 11, 545-554. [CrossRef]

6. Savolainen, J.; Collan, M. How Additive Manufacturing Technology Changes Business Models?-Review of Literature. Addit. Manuf. 2020, 32, 101070. [CrossRef]

7. Popescu, D.; Zapciu, A.; Amza, C.; Baciu, F.; Marinescu, R. FDM process parameters influence over the mechanical properties of polymer specimens: A review. Polym. Test. 2018, 69, 157-166. [CrossRef]

8. Bhadeshia, H.K.D.H. Additive manufacturing. Mater. Sci. Technol. 2016, 32, 615-616. [CrossRef]

9. Gisario, A.; Kazarian, M.; Martina, F.; Mehrpouya, M. Metal additive manufacturing in the commercial aviation industry: A review. J. Manuf. Syst. 2019, 53, 124-149. [CrossRef]

10. Vairis, A.; Petousis, M.; Vidakis, N.; Savvakis, K. On the Strain Rate Sensitivity of Abs and Abs Plus Fused Deposition Modeling Parts. J. Mater. Eng. Perform. 2016, 25, 3558-3565. [CrossRef]

11. Vidakis, N.; Petousis, M.; Tzounis, L.; Maniadi, A.; Velidakis, E.; Mountakis, N.; Kechagias, J.D. Sustainable additive manufacturing: Mechanical response of polyamide 12 over multiple recycling processes. Materials 2021, 14, 466. [CrossRef]

12. Manapat, J.Z.; Chen, Q.; Ye, P.; Advincula, R.C. 3D Printing of Polymer Nanocomposites via Stereolithography. Macromol. Mater. Eng. 2017, 302, 1600553. [CrossRef]

13. Wu, H.; Fahy, W.P.; Kim, S.; Kim, H.; Zhao, N.; Pilato, L.; Kafi, A.; Bateman, S.; Koo, J.H. Recent developments in polymers/polymer nanocomposites for additive manufacturing. Prog. Mater. Sci. 2020, 111, 100638. [CrossRef]

14. Vidakis, N.; Petousis, M.; Velidakis, E.; Mountakis, N.; Tzounis, L.; Liebscher, M.; Grammatikos, S.A. Enhanced mechanical, thermal, and antimicrobial properties of additively manufactured polylactic acid with optimized nano-silica content. Nanomaterials 2021, 11, 1012. [CrossRef]

15. Zhang, J.; Wang, J.; Dong, S.; Yu, X.; Han, B. A review of the current progress and application of 3D printed concrete. Compos. Part A Appl. Sci. Manuf. 2019, 125, 105533. [CrossRef] 
16. Mubarak, S.; Dhamodharan, D.; B Kale, M.; Divakaran, N.; Senthil, T.; Wu, L.; Wang, J. A Novel Approach to Enhance Mechanical and Thermal Properties of SLA 3D Printed Structure by Incorporation of Metal-Metal Oxide Nanoparticles. Nanomaterials 2020, 10, 217. [CrossRef] [PubMed]

17. Ma, X.L. Research on application of SLA technology in the 3D printing technology. Appl. Mech. Mater. 2013, 401-403, 938-941. [CrossRef]

18. Borrello, J.; Nasser, P.; Iatridis, J.C.; Costa, K.D. 3D printing a mechanically-tunable acrylate resin on a commercial DLP-SLA printer. Addit. Manuf. 2018, 23, 374-380. [CrossRef] [PubMed]

19. Msallem, B.; Sharma, N.; Cao, S.; Halbeisen, F.S.; Zeilhofer, H.-F.; Thieringer, F.M. Evaluation of the Dimensional Accuracy of 3D-Printed Anatomical Mandibular Models Using. J. Clin. Med. 2020, 9, 817. [CrossRef] [PubMed]

20. Slapnik, J.; Pulko, I. Tailoring properties of photopolymers for additive manufacturing with mixture design. Prog. Addit. Manuf. 2021, 6, 83-91. [CrossRef]

21. Martínez-Pellitero, S.; Castro, M.A.; Fernández-Abia, A.I.; González, S.; Cuesta, E. Analysis of influence factors on part quality in micro-SLA technology. Procedia Manuf. 2017, 13, 856-863. [CrossRef]

22. Son, K.; Lee, J.H.; Lee, K.B. Comparison of intaglio surface trueness of interim dental crowns fabricated with sla 3D printing, dlp 3d printing, and milling technologies. Healthcare 2021, 9, 983. [CrossRef]

23. Weng, Z.; Zhou, Y.; Lin, W.; Senthil, T.; Wu, L. Structure-Property Relationship of Nano Enhanced Stereolithography Resin for desktop SLA 3D printer. Key. Compos. Part A Appl. Sci. Manuf. 2016, 88, 234-242. [CrossRef]

24. Voet, V.S.D.; Strating, T.; Schnelting, G.H.M.; Dijkstra, P.; Tietema, M.; Xu, J.; Woortman, A.J.J.; Loos, K.; Jager, J.; Folkersma, R. Biobased Acrylate Photocurable Resin Formulation for Stereolithography 3D Printing. ACS Omega 2018, 3, 1403-1408. [CrossRef] [PubMed]

25. Shanmugasundaram, S.A.; Razmi, J.; Mian, M.J.; Ladani, L. Mechanical anisotropy and surface roughness in additively manufactured parts fabricated by stereolithography (SLA) using statistical analysis. Materials 2020, 13, 2496. [CrossRef] [PubMed]

26. Tareq, M.S.; Rahman, T.; Hossain, M.; Dorrington, P. Additive manufacturing and the COVID-19 challenges: An in-depth study. J. Manuf. Syst. 2021, 60, 787-798. [CrossRef]

27. Gao, X.; Qi, S.; Kuang, X.; Su, Y.; Li, J.; Wang, D. Fused filament fabrication of polymer materials: A review of interlayer bond. Addit. Manuf. 2021, 37, 101658. [CrossRef]

28. Liao, Y.; Liu, C.; Coppola, B.; Barra, G.; Di Maio, L.; Incarnato, L.; Lafdi, K. Effect of porosity and crystallinity on 3D printed PLA Properties. Polymers 2019, 11, 1487. [CrossRef] [PubMed]

29. Miedzińska, D.; Gieleta, R.; Małek, E. Experimental study of strength properties of SLA resins under low and high strain rates. Mech. Mater. 2020, 141, 103245. [CrossRef]

30. Wang, J.; Goyanes, A.; Gaisford, S.; Basit, A.W. Stereolithographic (SLA) 3D printing of oral modified-release dosage forms. Int. J. Pharm. 2016, 503, 207-212. [CrossRef]

31. Sa, L.; Kaiwu, L.; Shenggui, C.; Junzhong, Y.; Yongguang, J.; Lin, W.; Li, R. 3D printing dental composite resins with sustaining antibacterial ability. J. Mater. Sci. 2019, 54, 3309-3318. [CrossRef]

32. Zuniga, J.M.; Cortes, A. The role of additive manufacturing and antimicrobial polymers in the COVID-19 pandemic. Expert Rev. Med. Devices 2020, 17, 477-481. [CrossRef]

33. Larrañeta, E.; Dominguez-Robles, J.; Lamprou, D.A. Additive Manufacturing Can Assist in the Fight against COVID-19 and Other Pandemics and Impact on the Global Supply Chain. 3D Print. Addit. Manuf. 2020, 7, 100-103. [CrossRef]

34. Bishop, E.G.; Leigh, S.J. Using large-scale additive manufacturing (LSAM) as a bridge manufacturing process in response to shortages in PPE during the COVID-19 outbreak. Int. J. Bioprinting 2020, 6, 51-58. [CrossRef] [PubMed]

35. Advincula, R.C.; Dizon, J.R.C.; Chen, Q.; Niu, I.; Chung, J.; Kilpatrick, L.; Newman, R. Additive manufacturing for COVID-19: Devices, materials, prospects, and challenges. MRS Commun. 2020, 10, 413-427. [CrossRef] [PubMed]

36. Vidakis, N.; Petousis, M.; Tzounis, L.; Velidakis, E.; Mountakis, N.; Grammatikos, S.A. Polyamide 12/Multiwalled Carbon Nanotube and Carbon Black Nanocomposites Manufactured by 3D Printing Fused Filament Fabrication: A Comparison of the Electrical, Thermoelectric, and Mechanical Properties. C 2021, 7, 38. [CrossRef]

37. Diment, L.E.; Thompson, M.S.; Bergmann, J.H.M. Clinical efficacy and effectiveness of 3D printing: A systematic review. BMJ Open 2017, 7, e016891. [CrossRef]

38. Patel, P.; Gohil, P. Role of additive manufacturing in medical application COVID-19 scenario: India case study. J. Manuf. Syst. 2021, 60, 811-822. [CrossRef]

39. Morrison, R.J.; Kashlan, K.N.; Flanangan, C.L.; Wright, J.K.; Green, G.E.; Hollister, S.J.; Weatherwax, K.J. Regulatory Considerations in the Design and Manufacturing of ImplanTable 3D-Printed Medical Devices. Clin. Transl. Sci. 2015, 8, 594-600. [CrossRef]

40. Campbell, T.A.; Ivanova, O.S. 3D printing of multifunctional nanocomposites. Nano Today 2013, 8, 119-120. [CrossRef]

41. Vidakis, N.; Maniadi, A.; Petousis, M.; Vamvakaki, M.; Kenanakis, G.; Koudoumas, E. Mechanical and Electrical Properties Investigation of 3D-Printed Acrylonitrile-Butadiene-Styrene Graphene and Carbon Nanocomposites. J. Mater. Eng. Perform. 2020, 29, 1909-1918. [CrossRef] 
42. Conrad, M.; De Doncker, R.W.; Schniedenharn, M.; Diatlov, A. Packaging for power semiconductors based on the 3D printing technology Selective Laser Melting. In Proceedings of the 2014 16th European Conference on Power Electronics and Applications, EPE-ECCE Europe 2014, Lappeenranta, Finland, 26-28 August 2014; Institute of Electrical and Electronics Engineers Inc.: New York, NY, USA, 2014.

43. Vidakis, N.; Petousis, M.; Velidakis, E.; Mountakis, N.; Fischer-griffiths, P.E.; Grammatikos, S.; Tzounis, L. Fused Filament Fabrication Three-Dimensional Printing Multi-Functional of Polylactic Acid/Carbon Black Nanocomposites. C 2021, 7, 52. [CrossRef]

44. Ivanova, O.; Williams, C.; Campbell, T. Additive manufacturing (AM) and nanotechnology: Promises and challenges. Rapid Prototyp. J. 2013, 19, 353-364. [CrossRef]

45. Skorski, M.R.; Esenther, J.M.; Ahmed, Z.; Miller, A.E.; Hartings, M.R. The chemical, mechanical, and physical properties of 3D printed materials composed of $\mathrm{TiO}_{2}$-ABS nanocomposites. Sci. Technol. Adv. Mater. 2016, 17, 89-97. [CrossRef] [PubMed]

46. Vidakis, N.; Petousis, M.; Velidakis, E.; Tzounis, L.; Mountakis, N.; Kechagias, J.; Grammatikos, S. Optimization of the filler concentration on fused filament fabrication 3d printed polypropylene with titanium dioxide nanocomposites. Materials 2021, 14, 3076. [CrossRef]

47. Ferreira, I.; Machado, M.; Alves, F.; Torres Marques, A. A review on fibre reinforced composite printing via FFF. Rapid Prototyp. J. 2019, 25, 972-988. [CrossRef]

48. Vidakis, N.; Petousis, M.; Maniadi, A.; Koudoumas, E.; Liebscher, M.; Tzounis, L. Mechanical properties of 3D-printed acrylonitrilebutadiene-styrene $\mathrm{TiO}_{2}$ and ATO nanocomposites. Polymers 2020, 12, 1589. [CrossRef] [PubMed]

49. Alam, F.; Shukla, V.R.; Varadarajan, K.M.; Kumar, S. Microarchitected 3D printed polylactic acid (PLA) nanocomposite scaffolds for biomedical applications. J. Mech. Behav. Biomed. Mater. 2020, 103, 103576. [CrossRef]

50. Redondo, E.; Pumera, M. Fully metallic copper 3D-printed electrodes via sintering for electrocatalytic biosensing. Appl. Mater. Today 2021, 25, 101253. [CrossRef]

51. Daoush, W.M.; Lim, B.K.; Mo, C.B.; Nam, D.H.; Hong, S.H. Electrical and mechanical properties of carbon nanotube reinforced copper nanocomposites fabricated by electroless deposition process. Mater. Sci. Eng. A 2009, 513-514, 247-253. [CrossRef]

52. Din, M.I.; Rehan, R. Synthesis, Characterization, and Applications of Copper Nanoparticles. Anal. Lett. 2017, 50, 50-62. [CrossRef]

53. Laureto, J.; Tomasi, J.; King, J.A.; Pearce, J.M. Thermal properties of 3-D printed polylactic acid-metal composites. Prog. Addit. Manuf. 2017, 2, 57-71. [CrossRef]

54. Ruparelia, J.P.; Chatterjee, A.K.; Duttagupta, S.P.; Mukherji, S. Strain specificity in antimicrobial activity of silver and copper nanoparticles. Acta Biomater. 2008, 4, 707-716. [CrossRef]

55. Tu, J.P.; Yang, Y.Z.; Wang, L.Y.; Ma, X.C.; Zhang, X.B. Tribological properties of carbon-nanotube-reinforced copper composites. Tribol. Lett. 2001, 10, 225-228. [CrossRef]

56. Tang, Y.; Yang, X.; Wang, R.; Li, M. Enhancement of the mechanical properties of graphene-copper composites with graphenenickel hybrids. Mater. Sci. Eng. A 2014, 599, 247-254. [CrossRef] 